\title{
Analysis of Trends in Daily and Overnight Temperature Over Iran's Zayanderud River Basin
}

\author{
${ }^{1}$ Ali Zahraei, ${ }^{2}$ Sara Saadati, ${ }^{3}$ Saeid Eslamian and ${ }^{3}$ Kaveh Ostad-Ali-Askari \\ ${ }^{1}$ Department of Irrigation and Drainage Engineering, College of Abureyhan, University of Tehran, Tehran, Iran \\ ${ }^{2}$ Department of Watershed Engineering, University of Tehran, Tehran, Iran \\ ${ }^{3}$ Department of Water Engineering, College of Agriculture, Isfahan University of Technology, Isfahan 84156-83111, Iran
}

\author{
Article history \\ Received: 10-06-2018 \\ Revised: 19-07-2018 \\ Accepted: $30-07-2020$ \\ Corresponding Author: \\ Kaveh Ostad-Ali-Askari \\ Department of Water \\ Engineering, College of \\ Agriculture, Isfahan University \\ of Technology, Isfahan 84156- \\ 83111, Iran \\ Email: ostadaliaskari.k@of.iut.ac.ir \\ kaveh.oaa2000@gmail.com
}

\begin{abstract}
Daily and overnight temperature trends in annual time-scale for Zayanderud river basin using 37 meteorological stations were studied. According to the results the majority of trends in the time series of daily and overnight temperature were increasing. Warming trends in the overnight temperature were stronger than those in the daily temperature. The average of all stations in the daily and overnight trends was 0.003 and $0.014^{\circ} \mathrm{C}$ year $^{-1}$ respectively. Overall warming trends (daily-overnight) were consistent with increasing urbanization. Regional warming trends were more obvious in the more urbanized area in central and eastern basin. There were weak cooling trends in daily temperature in the western and southwestern basin with a colder and more rainfall climate.
\end{abstract}

Keywords: Climate Change, Daily and Overnight Temperature, Trend, Zayanderud River Basin, Iran

\section{Introduction}

This glance inspects the straight results of climate change on the environment. Temperature is identified as the prevailing abiotic component instantly affecting Environmentals. Temperature immediately affects progress, durability, range and amplitude. The primary result of temperature in temperate areas is to impact winter survival; the two components do not presently do in tandem. The World Health Organization approximates that the warming and precipitation movements due to anthropogenic climate change. Doubt stays in assigning to the development to climate change, owing to lack of long-time, high-quality data sets as well as the large impact of socio-economic components and alters in invioability. Air modality is forcefully related on weather and is therefore touchy to climate change. We inspect these various ways and their consequences. The later climate is anticipated to be more static, owing to a weaker global circulation and a reducing alternation of mid-latitude cyclones.

Climate change is as result of the increase or decrease of climatic parameters over a long period of time. Climatic measurer especially temperature and precipitation tends are able to show climate change. Various studies have done on climate to identify possible trends in meteorological parameters using statistical approaches (Serrano et al., 1999; Zheng et al., 1997; Schlünzen et al., 2010; Volodin and Yurova, 2013) and all of them pointed to a general warming trend in the temperature. In addition, International Panel on Climate Change (IPCC) has reported that global surface temperature change for the end of the 21st century will be in the range of $1.5-2.0^{\circ} \mathrm{C}$ (IPCC, 2013). The results of the studies are as follows: Altin et al. (2012) studied temperature fluctuation in the Central Anatolia region of Turkey. They showed a significant increase in mean temperature by $0.4^{\circ} \mathrm{C}$ decade ${ }^{-1}$. Martínez et al. (2010) studied daily temperature trend in Catalonia, Spain during 1975-2004. The results of this study indicated an increase in annual temperature by $0.5^{\circ} \mathrm{C}$ decade $^{-1}$. Ben-Gai et al. (1999) exhibited that daily and overnight temperature of Israel from 1964 to 1994 significantly decreased during winter and fall and increased during spring and summer. Romero-Higareda et al. (2014) investigated 9 temperature variables in northwestern Mexico and reported warming trend in the spring and summer. Nie et al. (2012) studied temporal and spatial variations of temperature and precipitation in Guangx and represented that the annual extreme temperature increased over the period 1960-2009. Ahmed et al. (2014) analyzed maximum and minimum temperature trends during 1941-2005 in Ontario, Canada. They pointed out an increase in maximum temperature in the 
seasonal and annual scale. Domroes and El-Tantawi (2005) analyzed annual mean temperature trends in Egypt and found decreasing trends in the north and increasing trends in the south of Egypt. Hasanean and AL-Khalaf (2012) studied the variability of wintertime temperature over the Kingdom of Saudi Arabia during 1978-2008 and indicated a warming trend at the most of stations a significant warming trend after the year 1997 with a rate of $0.03^{\circ} \mathrm{C} /$ year. Almazroui et al. (2012) investigated seasonal temperature trends in the Arabian Peninsula and showed that $T_{\max }, T_{\text {mean }}$ and $T_{\min }$ have increased by $0.67^{\circ} \mathrm{C}, 0.51^{\circ} \mathrm{C}$ and $0.34^{\circ} \mathrm{C}$ per decade in the wet season and by $0.8^{\circ} \mathrm{C}, 0.72^{\circ} \mathrm{C}$ and $0.63^{\circ} \mathrm{C}$ in the dry season.

Recently, several studies have been carried out for analysis of temperature trend in Iran. Tabari and Talaee (2011) analyzed monthly minimum and maximum temperature trend of arid and semi-arid of Iran using Mann-Kendall test and represented that the rate of increase for annual maximum and minimum temperatures were $0.09^{\circ}$ and $0.444^{\circ} \mathrm{C}$ decade $^{-1}$ respectively. Zarenistanak et al. (2014) studied variation of temperature in Iran and predicted an increase of mean temperature between $1.69-6.88^{\circ} \mathrm{C}$ by 2100 over the south-western part of Iran. Tabari et al. (2012) conducted a study on the mean annual temperature in Iran (1966-2005) and reported that the magnitude of temperature trend was $0.22^{\circ} \mathrm{C} \mathrm{decade}{ }^{-1}$. Ghasemi (2015) investigated the variations in temperature during 19612010 in Iran and showed a dominating positive trend over the most parts of Iran with a magnitude from 0.09 to $0.38^{\circ} \mathrm{C}$ per decade. In addition to he pointed out $T_{\min }$ increases faster than $T_{\max }$. Azaranfar et al. (2009) studied the precipitation and temperature variation in Zayanderud basin using statistical methods and indicated temperature will increase over the period 2010-2039. Ataei et al. (2013) using 16 stations detected mean monthly temperature trend in Esfahan province for 50 years period and exhibited more than $50 \%$ of the province experienced increasing trend in June, July, August, November and December. Gandomkar (2011) evaluated the variation of mean annual temperature and precipitation during 1960-2005 in Zayanderud river basin and showed that temperature in central basin has increased significantly.

There are few researches on temperature trend analysis in Zayanderud basin which are limited to detect mean temperature trend. Changing in mean temperature is due to changes in $T_{\min }$ or $T_{\max }$ or to changes in both and understanding the long-term change in extreme temperature to the detection of climate change is important (Ren and Zhou, 2014; del Rio et al., 2007). The main objective of this study is the analysis of regional trends in $T_{\max }$ (daily temperature) and $T_{\min }$ (overnight temperature) in Zayanderud basin using statistical approaches. It is expected that the findings of this study lead to more accurate understand of temperature behavior in the Zayanderud basin.

\section{Data and Methods}

\section{Data}

\section{Zayanderud River Basin}

Zayanderud river basin is one of the semi-arid Iran's basins located in Esfahan province. The river is the only permanent river in central Iran and plays vital role to meet diversity of demands (industrial, agricultural, urban...). The area of the basin is over 41,000 square kilometers with a population over 5.3 million people. Zayanderud River originates from the Zagros Mountains in the western basin and ends in the Gavkhuni wetland in the eastern basin (Fig. 1). The climate of the upstream of the basin is cold and rainy but downstream of the basin has dry and low rainfall climate. Annual overnight and daily temperature of the basin is 5.7 and 20 . 5respectively also annual mean precipitation of the basin is $178 \mathrm{~mm}$. Stored runoff in Zayanderud dam (located in the upstream of the river) is the main source to supply water demands of the basin.

\section{Climatic Data}

The monthly data during 1951-2010 were received from Iran meteorological organization and ministry of energy. There are 113 stations located in Zayanderud basin and around. Record lengths of these stations vary between 5 to 60 years. To enhance validity of the results, the stations selected based on a large record of data (more than 30 years), continuity of the records and appropriate distribution throughout the basin (Githui and Mutua, 2007; Ghahraman, 2007). On the basis of these criteria 37 stations were selected to analysis in this study. All records started from 1950s, 1960s, 1970s and 1980s to 2010. Twoannual temperature variables were used to analyze the trend in the basin:

1- The minimum temperature or overnight temperature $\left(T_{\min }\right)$

2- The maximum temperature or daily temperature $\left(T_{\max }\right)$

To analysis the homogeneity of the records, double-mass curve (Kohler, 1949) was used for each station. The results of double-mass curve showed that there are no obvious breakpoints in time series. There were a few gaps in selected stations. To fill these gaps, the recorded data in neighbor stations with high correlation were used. 


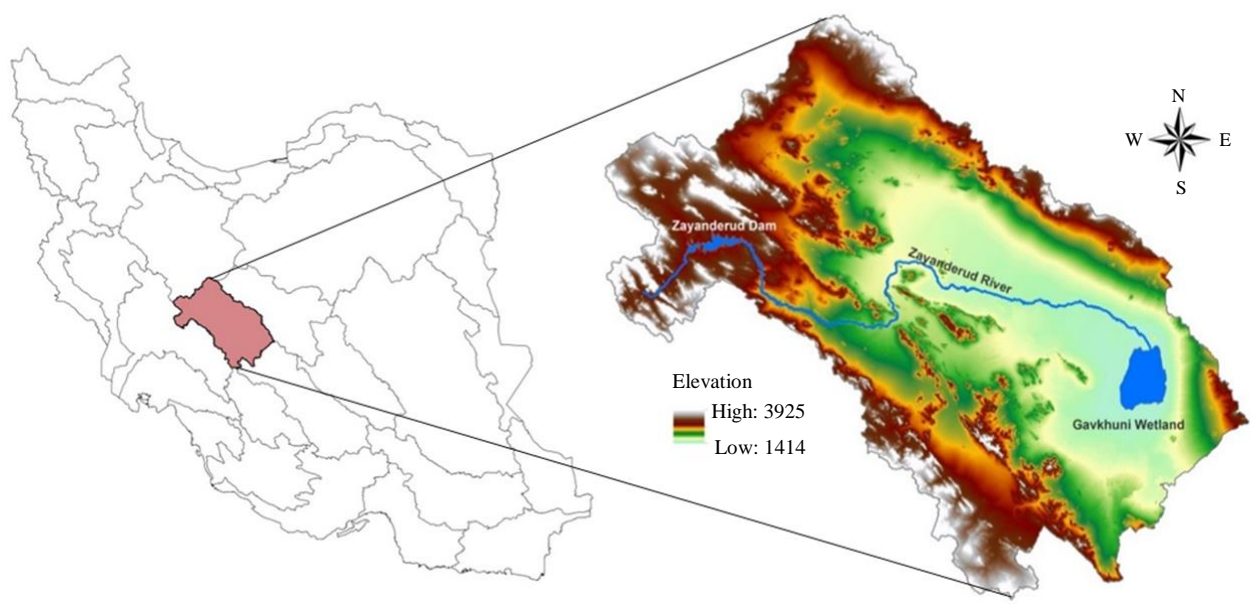

Fig. 1: Location of Zayanderud river basin in Iran

\section{Methods}

\section{Mann-Kendall Test}

The Mann-Kendall test is a non-parametric test to identify the significance of trends in hydrometeorological time series data (Islam, 2015). The test was first developed by (Mann, 1945) and then (Kendall, 1975) derived the statistical distribution of the test. The Mann-Kendall test formulation follows as: $(f(x)=\operatorname{sgn} x$, signum function, evaluating the definite integral of signum function yields:

$$
S=\sum_{i=1}^{n-1} \sum_{j=i+1}^{n} \operatorname{sgn}\left(x_{j}-x_{j}\right)
$$

In the Equation 1, $N$ is the total number of data $x_{i}$ and $x_{j}$ are the value of $i$ and $j$ data in time series $(j>i)$. Function $\operatorname{sgn}\left(x_{j}-x_{j}\right)$ is defined as follows:

$$
\operatorname{sgn}\left(x_{j}-x_{i}\right)= \begin{cases}+1 & \text { if }\left(x_{j}-x_{i}\right)>0 \\ 0 & \text { if }\left(x_{j}-x_{i}\right)=0 \\ -1 & \text { if }\left(x_{j}-x_{i}\right)<0\end{cases}
$$

The variance is also calculated from the following equation:

$$
V(S)=\frac{n(n-1)(2 n+5)-\sum_{k=1}^{m} t_{k}\left(t_{k}-1\right)\left(2 t_{k}+5\right)}{18}
$$

In Equation 3, $n$ is the number of data points, $m$ is the number of tied groups and $t_{k}$ denotes the number of ties of extent $k$. A tied group is a set of sample data having the same value. In cases where the sample size $n>10$, the standard normal test statistic $Z_{S}$ is computed using Equation 4: $S=$ the standard normal test statistic:

$$
Z_{S}=\left\{\begin{array}{cc}
\frac{S-1}{\sqrt{V(S)}} & \text { if } S>0 \\
0 & \text { f } S=0 \\
\frac{S+1}{\sqrt{V(S)}} & \text { if } S<0
\end{array}\right.
$$

If a trend in temperature time series is statistically significant at $\alpha=0.05$ level (or 95\% confidence). The null hypothesis of no trend is rejected at the 5\% significance level if $|Z|>1.96$ (Islam, 2015; Partal and Kahya, 2006; Modarres and Silva, 2007).

\section{Sen's Slope Estimator}

The Mann-Kendal test does not provide an estimate of the magnitude of trend. For this purpose, in this study we evaluated the magnitude of trend in each station by applying the $Q$ Sen's slope (Sen, 1968). At first data should be sorted in ascending order and then the following formula is applied to calculate Sen's slope $\left(Q_{k}\right)$ for $N$ pairs of data:

$Q_{k}=\frac{x_{j}-x_{i}}{j-i} \quad$ for $k=1,2, \ldots, N$

In Equation 5, $x_{j}$ and $x_{i}$ are the data values at times $j$ and $i(j>i)$ respectively. The total $N$ values of $Q_{k}$ are ranked from smallest to largest and the median of slope or Sen's slope estimator is computed as:

$Q_{\text {med }}= \begin{cases}Q_{\left[\frac{N+1}{2}\right]} & \text { if } N \text { is odd } \\ \frac{Q_{\left[\frac{N}{2}\right]}+Q_{\left[\frac{N+2}{2}\right]}}{2} & \text { if Nis even }\end{cases}$ 
$Q_{m e d}$ sign reflects data trend direction, while its value indicates the steepness of the trend (Sayemuzzaman and Jha, 2013; Gocic and Trajkovic, 2013; Islam, 2015).

\section{Serial Correlation Effect}

In order to remove the influence of the serial correlation the pre-whitened time series was used prior to applying $Q$ Sen's slope estimator and Mann-Kendal test. In this study, first serial correlation coefficient $\left(r_{1}\right)$ is calculated for time series $\left(x_{1}, x_{2}, x_{3} \ldots \ldots, x_{n}\right)$ with lag-1 according equation:

$r_{1}=\frac{\frac{1}{n-1} \sum_{i=1}^{n-1}\left(x_{i}-E\left(x_{i}\right)\right) \cdot\left(x_{i+1}-E\left(x_{i}\right)\right)}{\frac{1}{n} \sum_{i=1}^{n}\left(x_{i}-E\left(x_{i}\right)\right)^{2}}$

$$
E\left(x_{i}\right)=\frac{1}{n} \sum_{i=1}^{n}\left(x_{i}\right)
$$

where, $n$ is the number of observations and $E\left(x_{i}\right)$ is the mean of sample data. The following equation will be used for testing the time series data sets of serial correlation:

$\frac{-1-1.645 \sqrt{n}-2}{n-1}<r_{1}<\frac{-1+1.645 \sqrt{n}-2}{n-1}$

If $r_{1}$ is inside interval, the time series data set are considered as independent but if $r_{1}$ is outside the interval, the data has serial correlation. For independent time series, the Mann-Kendal test and the $Q$ Sen's slope can be used to the original observations. Otherwise, they will be used on pre-whitening time series $\left(x_{2}-r_{1} x_{3}, x_{3}-r_{1} x_{2} \ldots \ldots, x_{n}-r_{1} x_{n-1}\right)$ (Gocic and Trajkovic, 2013; Islam, 2015) (Fig. 2).

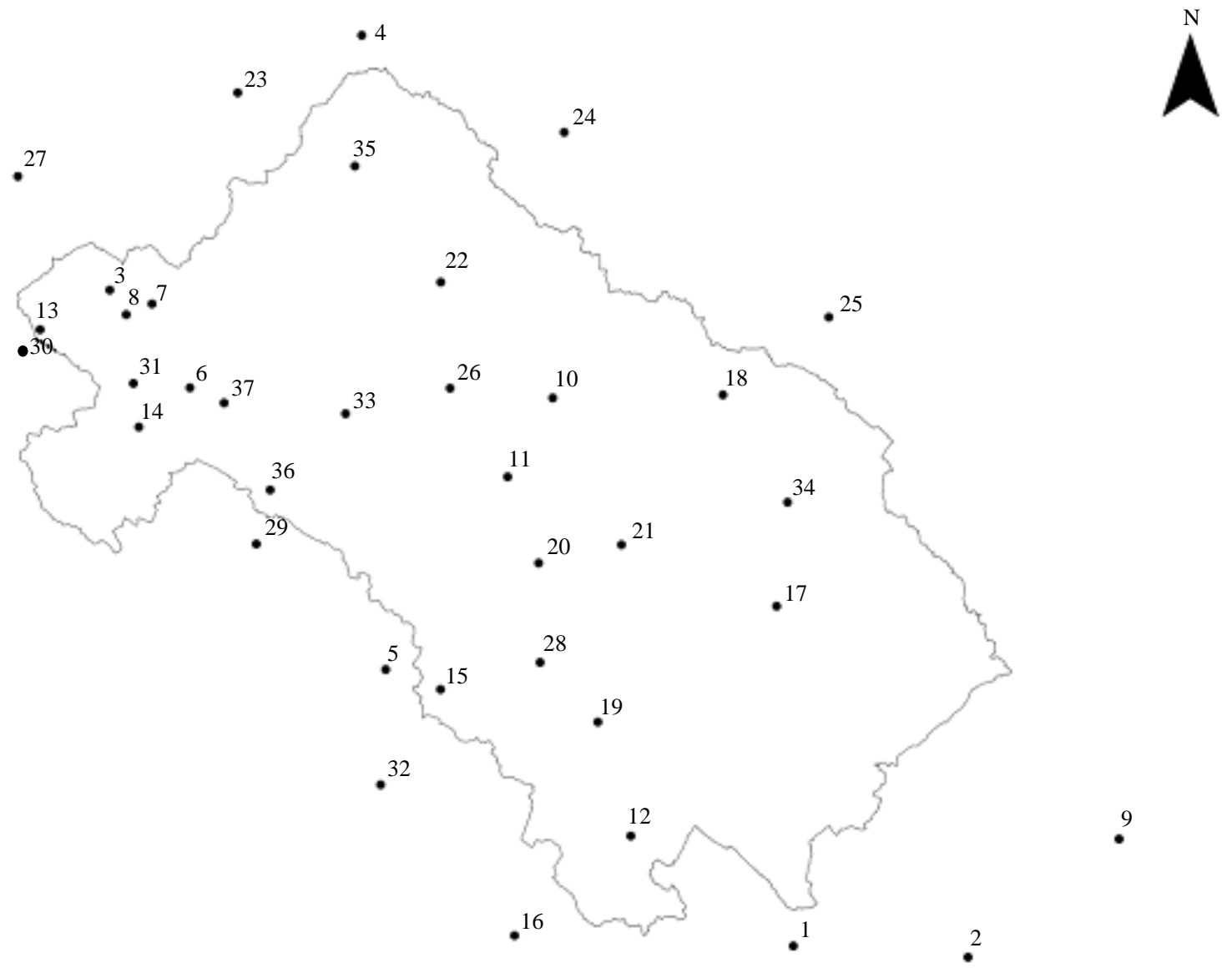

Fig. 2: The location of 37 weather stations in Zayanderud basin ;1: Abade; 2: Abarkooh; 3: Badijan; 4: Barzuk; 5: Borujen; 6: Chadegan; 7: Damane; 8: Daran; 9: Dehshir; 10: Esfahan(east); 11: Esfahan(south); 12: Ezadkhast; 13: Fereydunshahr; 14: Ghalesharokh; 15: Hamgin; 16: Hanna; 17: Hasanabad; 18: Koohpaye; 19: Maghsudbeyk; 20: Mahyar; 21: Mohamadabad; 22: Murchekhort; 23: Mute; 24: Natanz; 25: Neysianak; 26: Palayeshgah; 27: Sarabhende; 28: Shahreza; 29: Shahrkord; 30: Sibak; 31: Singerd; 32: Solegan; 33: Tiran; 34: Varzane; 35: Vazvan; 36: Polezamankhan; 37: Zayanderud 


\section{Results}

\section{Daily Temperature Trend}

Figure 3 shows the summarized outputs of $Q$ Sen's Slop estimator for annual daily, overnight temperature trend. According to the results, 21 out of 37 stations have increasing trend, 14 stations have experienced decreasing trend and 2 stations are without trend but only the increasing trend of the Tiran station is significant. Warming trends vary between $0.001-0.020^{\circ} \mathrm{C}$ year $^{-1}$ at all stations where Tiran and Abarkooh stations have the most and least of them respectively. Also, the variation of the decreasing trends are between $(-0.001)-(-0.014)^{\circ} \mathrm{C}$ year ${ }^{-1}$ where the highest and the lowest magnitude are seen at Ghalesharokh and Solegan stations respectively. Figure 4 indicates spatial distribution of trends. The most stations with increasing trend are clustered in the center and east of the basin and the majority of decreasing trends are seen in the western and southwestern basin.

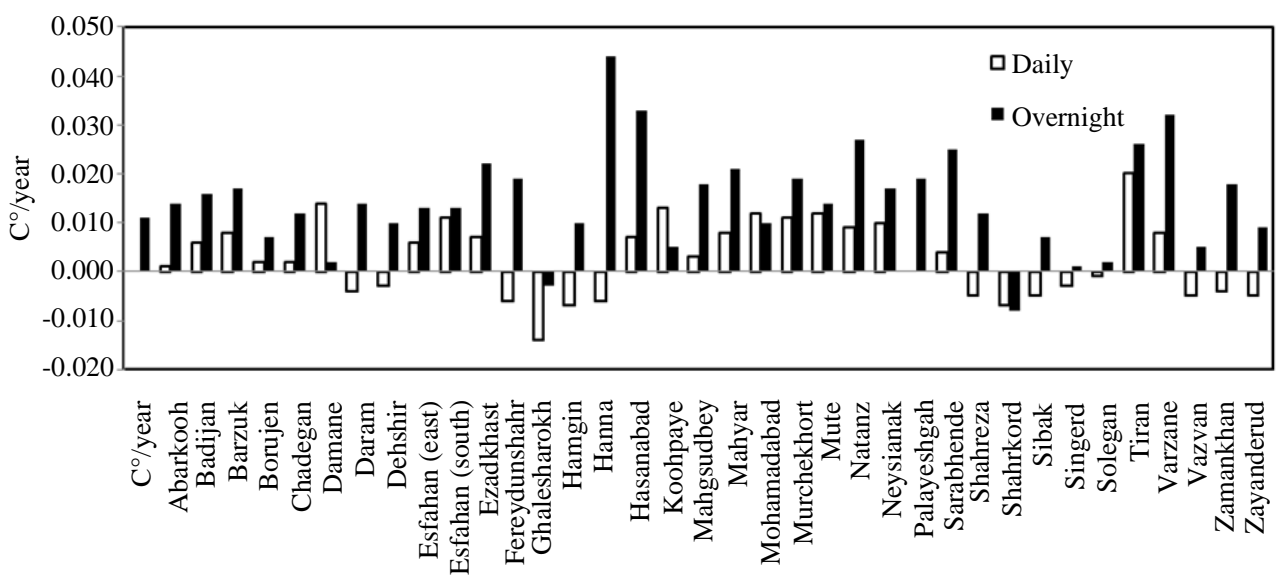

Fig. 3: Magnitude of daily and overnight temperature trend in stations

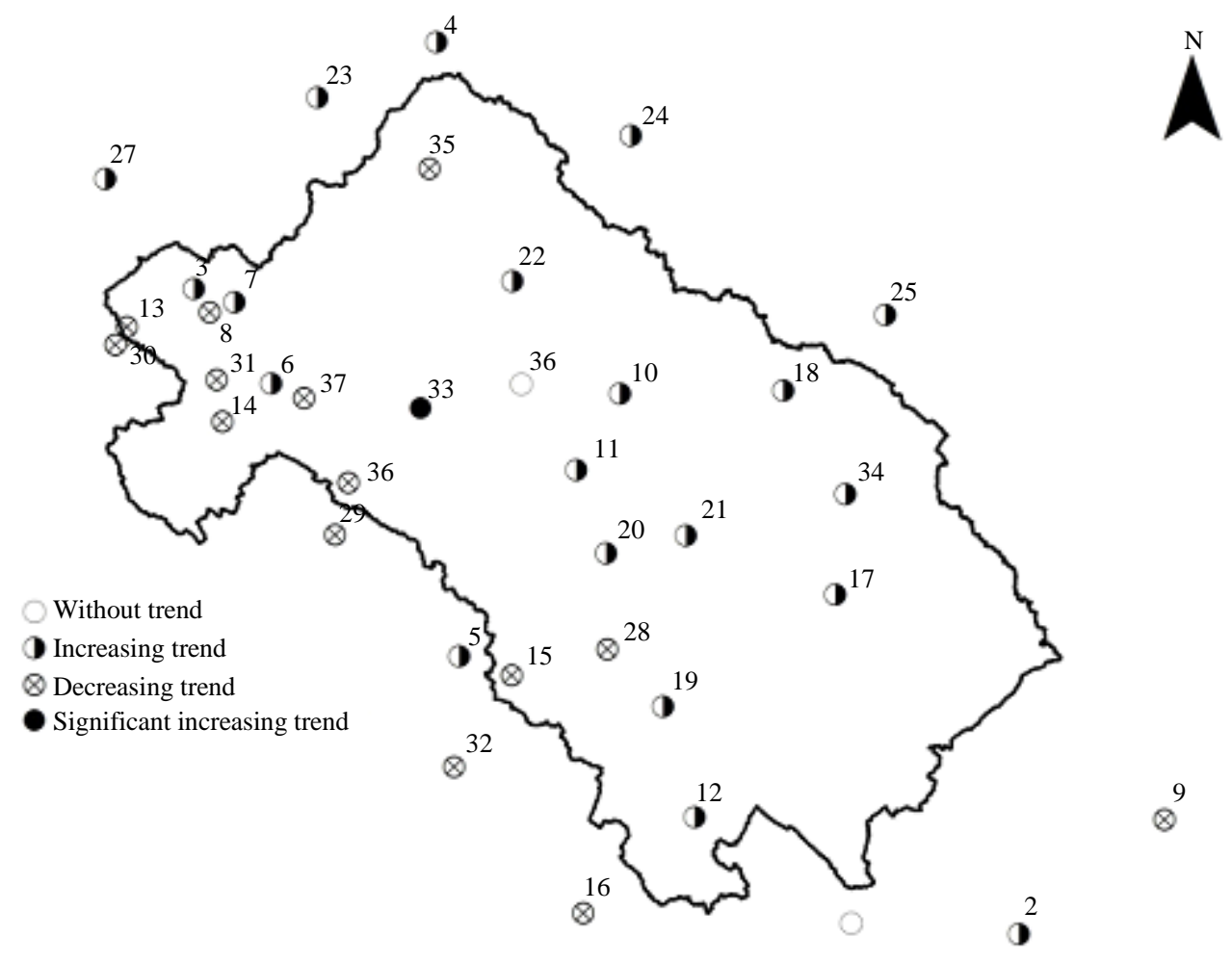

Fig. 4: Spatial distribution of daily temperature trends 


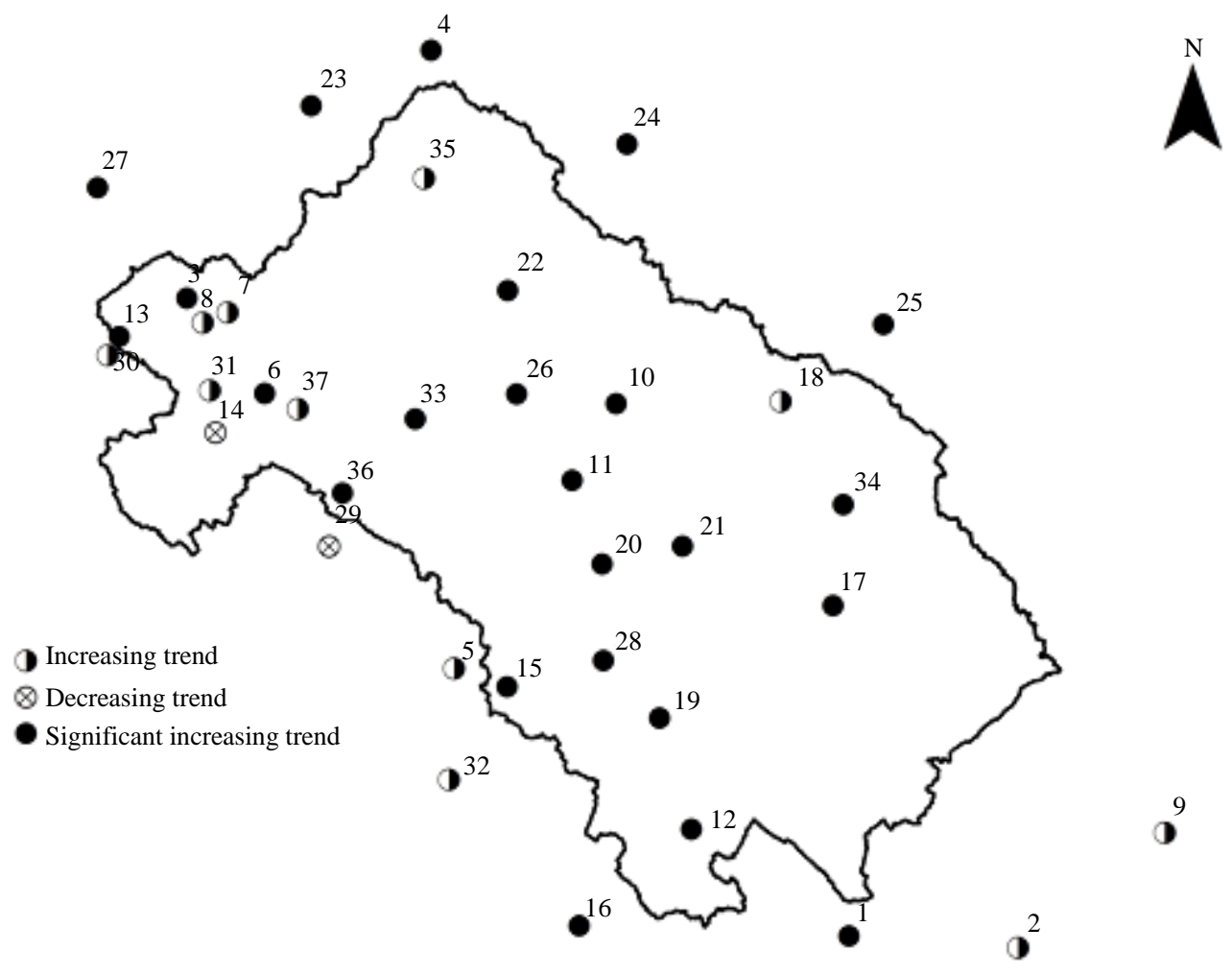

Fig. 5: Spatial distribution of overnight temperature trends

\section{Overnight Temperature Trend}

Overnight temperature trends in Fig. 3 represent 35 out of 37 stations have increasing trends and 2 other stations have decreasing trends. The 24 stations have significant increasing trends with a magnitude between $0.004-0.044^{\circ} \mathrm{C}$ year $^{-1}$. Hanna and Singerd stations have the most and least slopes respectively. Decreasing trends of stations are between $(-0.003)-(-0.008)^{\circ} \mathrm{C}$ year $^{-1}$ where the highest and lowest rate belong to Shahrekord and Ghalesharokh stations respectively. Spatial distribution of overnight trends in Fig. 5 shows the most areas of the basin have experienced significant increasing trends although in western basin significant trends are less observed.

\section{Discussion}

The amount of increase and decrease in trends at the stations of the basin explained in previous section. Trends in daily and overnight temperature averaged over whole 37 stations were 0.003 and $0.014^{\circ} \mathrm{C}$ year $^{-1}$ respectively. Former studies indicated that the average rate of warming in Iran for daily and overnight temperature is 0.015 and $0.034^{\circ} \mathrm{C}$ year $^{-1}$ (Ghasemi, 2015). In comparison with whole country, warming occurred in Zayanderud basin is smaller. Comparing trends shows that the increase of overnight temperature is observed in more number of the stations than daily temperature. Also, the magnitude of warming in overnight temperature is more than daily temperature. These results correspond with the results of previous studies in western Iran (Tabari and Marofi, 2011) and in arid and semi-arid regions of Iran (Tabari and Talaee, 2011). Previous studies were shown that changes in mean temperature can be due to change in daily or overnight temperature or both of them (del Rio et al., 2007). It can be inferred that due to stronger warming trends in overnight temperature, the observed increasing of mean temperature in the basin (Gandomkar, 2011) mainly is as result of the increase in overnight temperature. According to previous studies the asymmetry between overnight and daily warming refers to vertical stability of the atmospheric boundary layer. During the night, long wave radiation and heat fluxes dominate heat loss. The increase of greenhouse gases will result in enhanced re-radiation back towards the surface and therefore warming overnight temperatures. In the daytime, shortwave radiation dominates. The enhanced surface heating cause to greater mixing, reduce near-surface greenhouse gas concentration which will diffuse excessive heat and then decrease temperature anomaly (Malamud et al., 2011; Huang and Lu, 2015). 


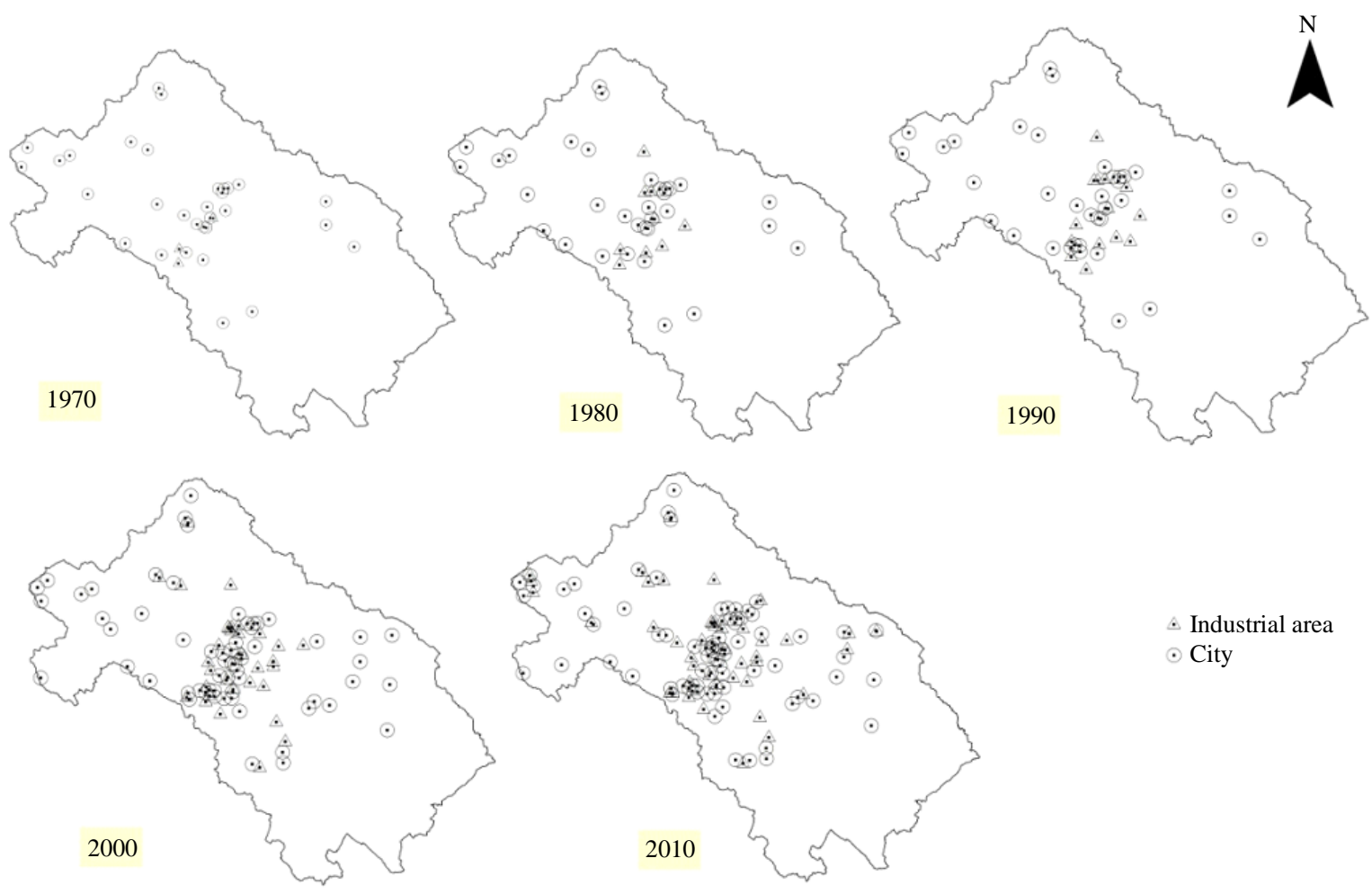

Fig. 6: The number of the cities and industrial areas in the Zayanderud basin (1970-2010)

Daily and overnight temperatures are two components of DTR (the difference between $T_{\max }$ and $T_{\min }$ ). In 12 stations of the basin daily temperature is decreasing and overnight temperature is increasing also in 14 stations warming in overnight temperature is faster than daily temperature. This led to decrease of DTR in these stations during the period. Former studies suggested that the interaction of cloud cover, soil moisture and rainfall may be triggers of change in DTR (del Rio et al., 2007; Dai et al., 1999). Decreasing DTR shows that the Earth's atmosphere is becoming more efficient in trapping terrestrial infrared radiation (Hamdi et al., 2009).

Development of the cities and industries in the last decades is the main occurred variations in relation to warming of the basin. Available information in this case from ministry of country and ministry of industries show that during four recent decades the number of industrial areas have increased from 3 to 45 units and the number of cities have increased from 31 to 77 cities (Fig. 6). Also, information of Statistical Center of Iran indicates urban population of the basin in 1995, 2005 and 2010 is $2.5,3.2$ and 3.5 million people. Indeed, owing to changing the rural area to urban area and expansion of the already urbanized cities the urban population of the basin during 15 years has increased by $40 \%$. According to (Oke, 1973) and (Fujibe, 2009) the intensity of urban heat island effect is linearly correlated with the logarithms of the population.
Heat emitted from the cities and industries leads to increasing temperature. Sources of this anthropogenic heat include industrial processes, power plants, combustion process of vehicles, transferred heat from residential and commercial buildings (Sailor and Lu, 2004). In addition air pollution (greenhouse gases) as result of consuming more fossil fuel, expansion of the cities from non-construction land to construction land with high buildings (absorb more radiation) can lead to rise temperature (Tabari and Talaee, 2011). Figure 6 shows the increase of cities and industrial area in central and eastern basin is more obvious than other part of the basin. Beside more than $90 \%$ of the basin's population settle in these areas and cities are more urbanized than other part of the basin. So, it appears due to more urbanization most of increasing or significant increasing trends are observed in the center and east of the basin.

Regarding decreasing trends, comparing two temperature variables indicates the decrease of daily temperature is observed at more stations than overnight. In addition, the rate of decrease in daily trends is more than overnight trends. Stations with decreasing trendsare seen mainly in the western and north westernbasin (Fig. 4). This area is the highest elevation part of the basin with a cold and rainy climate and a possible explanation for daily cooling is that the high albedo of clouds decreases the downward solar 
radiation during the day and thereby reduces $T_{\max }$ (Barkstrom, 1984; Karl et al., 1993; Dai et al., 1999; Smadi, 2006; Stone and Weaver, 2003).

Regional differences in magnitude of trends over the basin also may refer to physical geographic (e.g., topography, exposure), vegetation, land cover, land use, atmospheric circulation etc. Further investigation is needed to find the relation between trends and these factors (Turkeş and Sumer, 2004; Dhorde et al., 2009).

\section{Conclusion}

This study aimed to detect annual trends in daily and overnight temperatures time series for 37 stations in Iran's Zayanderud river basin using the Mann-Kendall test and the Sen's slope estimator. The results showed that most of the trends in the daily and overnight temperatures time series were positive, however, in general, the trend magnitudes of overnight temperature have been stronger than those in daily and mean temperature. The significant increasing trends were observed in the overnight temperature. Generally, most of positive trends were found in the central and eastern basin with a more urbanization than other part of the basin. Most of cooling trends were observed in the daily temperature, concentrated in the coldest and highest rainfall area (western and southwestern) of the basin but none of them are significant. The results of this study can contribute to managers of Zayanderud basin to obtain better insight about temperature variations in different part of the basin for reliable planning in supply water demands in the future. Climate is a significant component in environmental progress. And regarded as crucial property in environmental globally. Climate change is currently realized by most governmental organizations and scientists express this as a main public and environmental topic ahead of the universal crowd and assets. Here efforts have been made to consider and inspect the sight and status of environmental climate comfort of Zayandehroud River route at here, by climate tranquility indicator. This shows that some environmental goals at the western part of the river are at peril of diminution in number of climate tranquility days, due to a higher heating in western zones with a highlands and colder climate. The effects of these alters are obvious on environmental resources. The consequences disclose that the hydrological ways performed in this article can reliably approximate environmental water assignment for areas in arid and semi-arid areas when there is no precised knowledge about the biological demands of the Zayandehrud. Dependency of reservoir performance on the climate alteration happens mainly in areas, where agricultural request has a remarkable share of the total water requests. The mutability between requests that are depend on annual climate situations may be larger than the uncertainty related with other explanatory changeables in long-term performance of an irrigation dam. A territorial optimal assignment of water among various crops and irrigation units is progressed. Climate change is one of the most significant provocations among scientists and researchers. This event has a multiplex dynamic and time depending and it requires to an united long time study. It is defining trend of rainfall and temperature that can be effective for better water management in the study zone. In this article trend discovery of these changeables was applied in annual and seasonal time scales in the Zayandehrud Basin stations namely, Isfahan. Consequences showed that there are not any linear and nonlinear considerable trends among rainfall time series both annual and seasonal scale in the Zayandehrud basin except spring rainfall and summer rainfall.

\section{Acknowledgment}

We thank Department of Irrigation and Drainage Engineering, College of Abureyhan, University of Tehran, Tehran, Iran.

\section{Author's Contributions}

All authors equally contributed in this work.

\section{Ethics}

This study approved by Department of Irrigation and Drainage Engineering, College of Abureyhan, University of Tehran, Tehran, Iran.

\section{References}

Ahmed, S. I., Rudra, R., Dickinson, T., \& Ahmed, M. (2014). Trend and periodicity of temperature time series in Ontario. American Journal of Climate Change, 3(03), 272.

Almazroui, M., Islam, M. N., Jones, P. D., Athar, H., \& Rahman, M. A. (2012). Recent climate change in the Arabian Peninsula: seasonal rainfall and temperature climatology of Saudi Arabia for 1979-2009. Atmospheric Research, 111, 29-45.

Altin, T. B., Barak, B., \& Altin, B. N. (2012). Change in precipitation and temperature amounts over three decades in central Anatolia, Turkey.

Ataei, H., Hasheminasab, S., \& Cheraghi, S. (2013). Trend analysis of the average monthly temperature in Isfahan province. Bull. Environ., Pharmacol. Life Sci, 3, 98-102.

Azaranfar, A. Abrisham, A. and Tajreshi, M. (2009). Analysis of impact of climate change inprecipitation and temperature in Zayanderud Basin. 4th Iranian National Conference on Water Resource, Tehran, Iran. 
Barkstrom, B. R. (1984). The earth radiation budget experiment (ERBE). Bulletin of the American Meteorological Society, 65(11), 1170-1185.

Ben-Gai, T., Bitan, A., Manes, A., Alpert, P., \& Rubin, S. (1999). Temporal and spatial trends of temperature patterns in Israel. Theoretical and Applied Climatology, 64(3-4), 163-177.

Dai, A., Trenberth, K. E., \& Karl, T. R. (1999). Effects of clouds, soil moisture, precipitation \& water vapor on diurnal temperature range. Journal of Climate, 12(8), 2451-2473.

del Rio, S., Fraile, R., Herrero, L., \& Penas, A. (2007). Analysis of recent trends in mean maximum and minimum temperatures in a region of the $\mathrm{NW}$ of Spain (Castilla y Le n). Theoretical and Applied Climatology, 90(1-2), 1-12.

Dhorde, A., Dhorde, A., \& Gadgil, A. S. (2009). Longterm temperature trends at four largest cities of India during the twentieth century. J. Ind. Geophys. Union, 13(2), 85-97.

Domroes, M., \& El-Tantawi, A. (2005). Recent temporal and spatial temperature changes in Egypt. International Journal of Climatology: A Journal of the Royal Meteorological Society, 25(1), 51-63.

Fujibe, F. (2009). Detection of urban warming in recent temperature trends in Japan. International Journal of Climatology: A Journal of the Royal Meteorological Society, 29(12), 1811-1822.

Gandomkar, A. (2011). Investigating the precipitation and temperature change procedure in Zayanderood watershed. World Academy of Science, Engineering and Technology, 5, 43-47.

Ghahraman, B. (2007). Time trend in the mean annual temperature of Iran. Turkish journal of agriculture and forestry, 30(6), 439-448.

Ghasemi, A. R. (2015). Changes and trends in maximum, minimum and mean temperature series in Iran. Atmospheric Science Letters, 16(3), 366-372.

Githui, F. W., \& Mutua, F. (2007). Assessing the impacts of environmental change on the hydrology of the Nzoia catchment, in the Lake Victoria Basin (Doctoral dissertation).

Gocic, M., \& Trajkovic, S. (2013). Analysis of changes in meteorological variables using Mann-Kendall and Sen's slope estimator statistical tests in Serbia. Global and Planetary Change, 100, 172-182.

Hamdi, M. R., Abu-Allaban, M., Elshaieb, A., Jaber, M., \& Momani, N. M. (2009). Climate change in Jordan: a comprehensive examination approach. American Journal of Environmental Sciences, 5(1), 740-750.

Hasanean, H. M., \& Al-Khalaf, A. R. K. (2012). Variability of wintertime surface air temperature over the Kingdom of Saudi Arabia. Atmospheric and Climate Sciences, 2(03), 307.
Huang, Q., \& Lu, Y. (2015). The effect of urban heat island on climate warming in the Yangtze River Delta urban agglomeration in China. International journal of environmental research and public health, 12(8), 8773-8789.

IPCC. (2013). Climate change 2013: The physical science basis. In Contribution of Working Group I to the Fifth Assessment Report of the Intergovernmental Panel on Climate Change, Stocker, T.F. Qin, D. Plattner, G.K. Tignor, M \& Allen, S.K. et al. (Eds.), Cambridge University Press, Cambridge, New York.

Islam, A. W. (2015). Rainy/non-rainy day pattern analysis for North Carolina. American Journal of Climate Change, 4(01), 1.

Karl, T. R., Jones, P. D., Knight, R. W., Kukla, G., Plummer, N., Razuvayev, V., ... \& Peterson, T. C. (1993). Asymmetric trends of daily maximum and minimum temperature. Papers in Natural Resources, 185.

Kendall, M. G. (1975). Rank correlation measures. Charles Griffin, London.

Kohler, M. A. (1949). On the use of double-mass analysis for testing the consistency of meteorological records and for making required adjustments. Bulletin of the American Meteorological Society, 30(5), 188-195.

Malamud, B. D., Turcotte, D. L., \& Grimmond, C. S. B. (2011). Temperature trends at the Mauna Loa observatory, Hawaii. Climate of the Past, 7(3), 975-983.

Mann, H. B. (1945). Nonparametric tests against trend. Econometrica: Journal of the econometric society, 245-259.

Martínez, M. D., Serra, C., Burgueño, A., \& Lana, X. (2010). Time trends of daily maximum and minimum temperatures in Catalonia (ne Spain) for the period 1975-2004. International Journal of Climatology: A Journal of the Royal Meteorological Society, 30(2), 267-290.

Modarres, R., \& da Silva, V. D. P. R. (2007). Rainfall trends in arid and semi-arid regions of Iran. Journal of arid environments, 70(2), 344-355.

Nie, C., Li, H., Yang, L., Ye, B., Dai, E., Wu, S., ... \& Liao, Y. (2012). Spatial and temporal changes in extreme temperature and extreme precipitation in Guangxi. Quaternary International, 263, 162-171.

Oke, T. R. (1973). City size and the urban heat island. Atmospheric Environment (1967), 7(8), 769-779.

Partal, T., \& Kahya, E. (2006). Trend analysis in Turkish precipitation data. Hydrological Processes: An International Journal, 20(9), 2011-2026.

Ren, G., \& Zhou, Y. (2014). Urbanization effect on trends of extreme temperature indices of national stations over mainland China, 1961-2008. Journal of Climate, 27(6), 2340-2360. 
Romero-Higareda, C. E., Peinado-Guevara, L. I., Campista-León, S., Cázarez-Martínez, J., SánchezZazueta, J. G., \& Sánchez-Bañuelos, R. (2014). Temperature Trend Analysis in the North Pacific Watershed in Mexico. American Journal of Climate Change, 3(03), 306.

Sailor, D. J., \& Lu, L. (2004). A top-down methodology for developing diurnal and seasonal anthropogenic heating profiles for urban areas. Atmospheric environment, 38(17), 2737-2748.

Smadi, M. M. (2006). Observed abrupt changes in minimum and maximum temperatures in Jordan in the 20th century. Am. J. Environ. Sci, 2(3), 114-120.

Sayemuzzaman, M., \& Jha, M. K. (2013). Monthly time series trend analysis of temperature and precipitation in North Carolina Authors: Mohammad Sayemuzzaman1; Manoj K Jha2 1Presenting author: PhD candidate, Energy and Environmental System department, 2Assistant Professor, Department of Civil, Architectural and Environmental Engineering, North Carolina A\&T State University. AGUFM, 2013, GC23A-0900.

Schlünzen, K. H., Hoffmann, P., Rosenhagen, G., \& Riecke, W. (2010). Long-term changes and regional differences in temperature and precipitation in the metropolitan area of Hamburg. International journal of climatology, 30(8), 1121-1136.

Sen, P. K. (1968). E stim ates of the R egression C oefficient based on $\mathrm{K}$ en $\mathrm{d}$ all's $\mathrm{T}$ au. J. A $\mathrm{m}$ er. Statist. Assoc, 63, 1379-1389.

Serrano, A., Mateos, V. L., \& Garcia, J. A. (1999). Trend analysis of monthly precipitation over the Iberian Peninsula for the period 1921-1995. Physics and Chemistry of the Earth, Part B: Hydrology, Oceans and Atmosphere, 24(1-2), 85-90.
Stone, D., \& Weaver, A. (2003). Factors contributing to diurnal temperature range trends in twentieth and twenty-first century simulations of the CCCma coupled model. Climate Dynamics, 20(5), 435-445.

Tabari, H., \& Talaee, P. H. (2011). Analysis of trends in temperature data in arid and semi-arid regions of Iran. Global and Planetary Change, 79(1-2), 1-10.

Tabari, H., Talaee, P. H., Ezani, A., \& Some'e, B. S. (2012). Shift changes and monotonic trends in autocorrelated temperature series over Iran. Theoretical and Applied Climatology, 109(1-2), 95-108.

Tabari, H., \& Marofi, S. (2011). Changes of pan evaporation in the west of Iran. Water Resources Management, 25(1), 97-111.

Turkeş, M., \& Sümer, U. M. (2004). Spatial and temporal patterns of trends and variability in diurnal temperature ranges of Turkey. Theoretical and Applied Climatology, 77(3-4), 195-227.

Volodin, E. M., \& Yurova, A. Y. (2013). Summer temperature standard deviation, skewness and strong positive temperature anomalies in the present day climate and under global warming conditions. Climate dynamics, 40(5-6), 1387-1398.

Zarenistanak, M., Dhorde, A. G., \& Kripalani, R. H. (2014). Temperature analysis over southwest Iran: trends and projections. Theoretical and applied climatology, 116(1-2), 103-117.

Zheng, X., Basher, R. E., \& Thompson, C. S. (1997). Trend detection in regional-mean temperature series: maximum, minimum, mean, diurnal range \& SST. Journal of climate, 10(2), 317-326. 